Article

\title{
Employment Effects of Renewable Energy Expansion on a Regional Level-First Results of a Model-Based Approach for Germany
}

\section{Philip Ulrich *, Martin Distelkamp and Ulrike Lehr}

Economic Structure Research, Heinrichstr 30, 49080 Osnabrück, Germany;

E-Mails: distelkamp@gws-os.com (M.D.); lehr@gws-os.com (U.L.)

* Author to whom correspondence should be addressed; E-Mail: ulrich@gws-os.com; Tel.: +49-541-40933-200; Fax: +49-541-40933-110.

Received: 2 December 2011; in revised form: 18 January 2012 / Accepted: 29 January 2012 / Published: 7 February 2012

\begin{abstract}
National studies have shown that both gross and net effects of the expansion of energy from renewable sources on employment are positive for Germany. These modeling approaches also revealed that this holds true for both present and future perspectives under certain assumptions on the development of exports, fossil fuel prices and national politics. Yet how are employment effects distributed within Germany? What components contribute to growth impacts on a regional level? To answer these questions (new) methods of regionalization were explored and developed for the example "wind energy onshore" for Germany's federal states. The main goal was to develop a methodology which is applicable to all renewable energy technologies in future research. For the quantification and projection, it was necessary to distinguish between jobs generated by domestic investments and exports on the one hand, and jobs for operation and maintenance of existing plants on the other hand. Further, direct and indirect employment is analyzed. The results show, that gross employment is particularly high in the northwestern regions of Germany. However, especially the indirect effects are spread out over the whole country. Regions in the south not only profit from the delivery of specific components, but also from other industry and service inputs.
\end{abstract}

Keywords: renewable energy sources; input-output-analysis; regional employment; regional allocation model; interregional intermediate demand 


\section{Introduction}

Since the year 2006 employment generated by the production of facilities for the use of renewable energy (RE) sources and their operation and maintenance has been the subject of several research projects hosted by the German Federal Ministry for the Environment, Nature Conservation and Nuclear Safety [1-4]. The body of literature from these research projects looks at gross employment comprising the jobs generated from increased production in the RE-industries and from operation and maintenance (O'Sullivan et al. (2011) for an ex-post analysis [5], Lehr et al. (2011) for future projections [3]), as well as overall net employment in the economy including negative budget and substitution effects. It shows that also the latter effects are positive. Staiß et al. [1] compare a scenario with a more rapid expansion of renewable energy use to a business as usual scenario; Kratzat et al. [2] and Lehr et al. [3] compare the German Lead Scenario with a Zero-RE-scenario. All studies exhibit positive net effects from these comparisons (cf. also Blazejczak et al. [6]). Lehr et al. [3] project up to 600,000 jobs in the renewable energy industry by 2030. These and other related studies show how political measures and national programs influence recent and future developments. However, programs regarding environmental, climate-protective and energy policies are established not only on a national level. In Germany all 16 federal states ("Bundesländer") have their own agendas and programs, which refer to aims for the expansion of RE-use [7]. Remarkably many of these regional programs not only imply commitments to national goals but to further efforts for more sustainability. They also associate goals for a cleaner energy supply with goals and revenues in terms of regional added value, innovation potentials and new jobs. Consequently the studies on regional employment effects generated by future developments in renewables are of special interest for regional energy and economic policies. But how many jobs are related to the expansion of a certain RE-technology in a region today? What industries are involved and how high is the local content of inputs for the production, construction and maintenance of installations? To answer these questions (new) methods of regionalization were explored and developed for the example "wind energy onshore" for Germany's federal states.

Unfortunately the "wind industry", as for all other RE-technologies, is not the subject of official statistics. Its activities are spread over many different sectors and branches (e.g., machinery, metal products). In addition, talking about gross employment effects means to account not only for the (direct) employment within the sector, but also for the indirect effects induced by the intermediate demand. Therefore, the nationwide approximation of regional employment effects combines the well-founded and established results from the national study [3] with a new regional approach, which takes into account spatial information on production and installation in a regional economic model. Based on this methodology further links to future projection can be elaborated for the regions.

This contribution reports from a pilot modeling exercise for one RE-technology. The following definitions and delimitations have to be taken into consideration:

- "Wind energy onshore" is one of the most important RE-technologies regarding employment impacts in Germany. Another motivation for the focus on this energy source in the pilot study is that the availability of surveys for the wind industry and related energy plants is quite good in comparison to other RE-technologies. Both "wind energy offshore" and all other 
technologies for the use of renewable energy sources were excluded for the following regional study.

- The value chain analyzed starts with the intermediate inputs for the production of wind turbines including all components, followed by the production and installation of the facility. It includes the process of energy production, which involves all activities related to the operation and maintenance of the facility. For this operation phase also intermediate inputs are taken into consideration. The value chain does not include the inputs for the construction of production facilities for wind turbines (equipment).

- This paper concentrates on the status-quo of regional employment, but also shows some results of a projection up to the year 2030. These results do not represent forecasts and should not be over-interpreted as a political agenda for the federal states. Moreover, they are intended to give input to discussions both about the modeling approach and future impact factors and the regional distribution of RE-jobs.

After presenting the general approach of the regional model, the methodology for the assessment of both direct and indirect employment is described in the following section. In Section 3, the results for the year 2009 are presented in a similar arrangement. Section 4 summarizes main findings about possible future developments. In the end we conclude with a summary and an outlook. Both the methodology and the results of this study are documented in detail in a previous report [8].

\section{Approach to Estimate Direct and Indirect Employment in the Wind Onshore Sector}

The starting point of the analysis is an already established dataset with national values. These are derived from a recent study, which used both a large survey database and an economic model [3]. The survey of 1200 companies in the renewables sector in Germany was performed in 2008 . The economic model used in the national study not only enables analyses of gross and net effects on employment, but also performs future projections. PANTA RHEI is a version of the macroeconometric simulation and prognosis model INFORGE developed by GWS $\mathrm{mbH}$, which has been expanded to include an analysis of environmental economic issues [9].

National gross employment in the wind energy sector amounted to 102,100 persons in 2009 . Of those, 95,560 jobs are related to onshore technology. For the regional analysis, this total has to be broken down into several components, as the localization method varies with every effect-component. We distinguish employment generated by manufacturing on the one side and by operation and maintenance on the other hand. Further, we divide direct effects created by the production and use of facilities and indirect employment effects through manufacturers' and operators' intermediate demand. Indirect employment can be generated by suppliers for wind energy firms (first-round effect) or suppliers beyond the first stage of the value chain (further multipliers through intermediate demand). Table 1 gives an overview of the employment by component of effect and assigns the localization method, which was used to generate values for the 16 federal states in Germany.

On the one hand, the presented regionalization can be called a top-down approach, with the intention to identify regional shares of employment. On the other hand, indirect effects have to be generated in regional allocation models, which transfer macroeconomic relationships to the regional 
level. For all steps towards a regional analysis large regional and national datasets have to be used in the methodological framework.

Table 1. Components of gross employment impacts (wind energy onshore).

\begin{tabular}{|c|c|c|c|c|c|}
\hline \multirow[b]{2}{*}{ Wind energy onshore } & \multicolumn{2}{|c|}{ Production } & \multicolumn{2}{|c|}{ Operation and maintenance } & \multirow{2}{*}{$\begin{array}{l}\text { Total } \\
\text { Gross effect } \\
\text { employment, } \\
2009\end{array}$} \\
\hline & $\begin{array}{l}\text { Gross effect } \\
\text { employment, } \\
2009\end{array}$ & $\begin{array}{l}\text { Localization } \\
\text { method }\end{array}$ & $\begin{array}{c}\text { Gross effect } \\
\text { employment, } \\
2009 \\
\end{array}$ & $\begin{array}{l}\text { Localization } \\
\text { method }\end{array}$ & \\
\hline $\begin{array}{l}\text { Total } \\
\text { of which: }\end{array}$ & 78,310 & & 17,250 & & 95,560 \\
\hline Direct & 35,370 & DA & 4,740 & $\mathrm{HB}$ & 40,110 \\
\hline $\begin{array}{l}\text { Indirect } \\
\text { of which: }\end{array}$ & 42,940 & & 12,510 & & \\
\hline 1 st round effect & 18,820 & MB & 6,300 & MB & 25,120 \\
\hline Further multipliers & 24,120 & MB & 6,210 & MB & 30,330 \\
\hline $\begin{array}{l}\text { Three localization } \\
\text { methods: }\end{array}$ & \multicolumn{5}{|c|}{$\begin{array}{l}\mathrm{DA}=\text { evaluation of existing datasets and studies (data assessment) } \\
\mathrm{HB}=\text { hypothesis-based assessment } \\
\mathrm{MB}=\text { model-based assessment }\end{array}$} \\
\hline
\end{tabular}

\subsection{Regional Direct Employment Today}

Official statistics' classifications do not include industries or products directly related to "wind turbine production". A representative survey, including companies which generate the major part of their turnover with wind energy, is compulsory for a well-founded estimation. As the "big players" in wind industry and component suppliers are concentrated within Germany, survey data can only be significant if all these companies are included. Furthermore, only one or two years of development can lead to significant changes in distribution.

That is why the localization of directly employed persons in the manufacturing process of wind turbines is based on three major data sources: (1) The results of the above mentioned survey of companies in the renewables sector in Germany; (2) the results of existing case studies about employment in the federal states; and (3) indicators of a national study, which compares the states concerning factors of success for the use of renewable energy resources ("Bundesländer-Vergleichsstudie" [7]). These information sources were combined, as none of them offer a complete and consistent framework to derive the regional distribution of employment generated by manufacturing wind turbines and its major components.

Table 2. Two indicators of direct employment.

\begin{tabular}{ccc}
\hline $\begin{array}{c}\text { Major } \\
\text { regions }\end{array}$ & $\begin{array}{c}\text { Share of installed capacity of } \\
\text { wind turbines 2009 }\end{array}$ & $\begin{array}{c}\text { Producers of wind } \\
\text { turbines (Production sites) }\end{array}$ \\
\hline North & $36.8 \%$ & Enercon, Vestas, Nordex, \\
& $41.2 \%$ & GE Energy, RePower, Siemens \\
East & $18.4 \%$ & Enercon, Vestas, Nordex \\
West & $3.6 \%$ & Fuhrländer \\
South & & \\
\hline
\end{tabular}


The localization of directly employed persons in the process of operating and maintaining wind energy facilities is based on information about capacity installations within Germany. The method is based on the assumption that the regional share of direct employment is larger the more capacities are installed in the region. Furthermore, the share is, with minor relevance, linked to the locations of the producers of wind power systems (Enercon, Vestas, etc.). Table 2 shows two indicators of regional direct employment in an aggregated form.

\subsection{Regional Indirect Employment Today}

Contrary to direct employment, indirect employment is too complex to assess in surveys. Furthermore, indirect employment generated by the expansion of wind energy is not only a function of regional direct employment. This is due to the fact that inputs for production are not only delivered from that region. The localization of indirect effects must take into account both an input-ouput analysis, as well as a regional allocation and interaction model. For this reason, simple top-down approaches are not accurate for the purpose. Every region profits from manufacturing, operating and maintaining activities in their own region. However, others regions also do, as a certain share of input is delivered from other regions. For this purpose a multi-regional model based on 16 input-output tables and all regional trade shares would be the optimal solution. As in many other regional studies, regional data limitations lead to alternative approaches [10,11].

One major part of estimating regional indirect effects is input-output analysis. Following the methodology of the national study, first the demand for specialized input is calculated by using an input-vector, which represents the cost-structure of the given RE-technology [12]. The result is a demand-vector representing the "First round effect". The major primary inputs for the wind industry technology at this stage are electrical apparatus, fabricated metals and machinery. This demand then is used to calculate the demand for general inputs by using the national input-output table ("Further multipliers"). In between and after these steps the regional reallocation model is implemented (see Figure 1).

Figure 1. Methodological framework for estimating regional indirect employment.

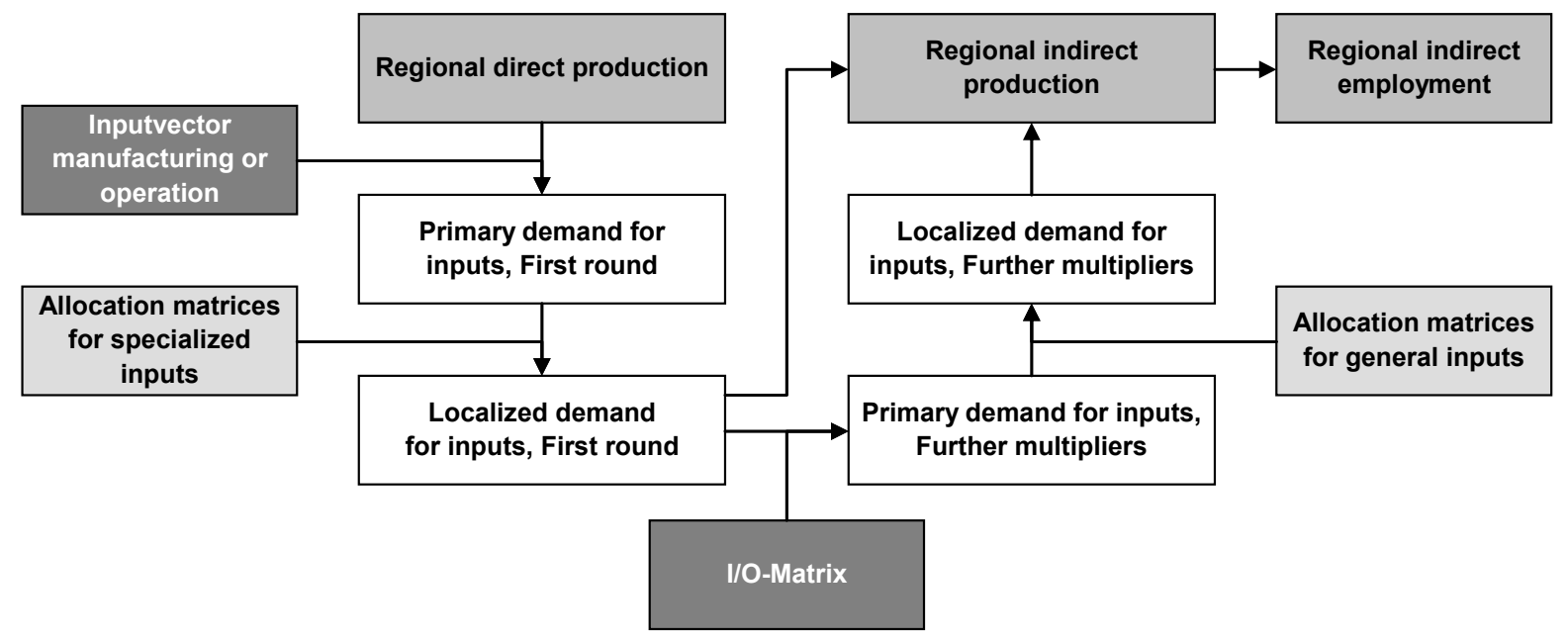


The allocation model is based on different assumptions, as regional input-output tables are not available and interregional linkages cannot be derived from official data. Nevertheless, there are several determinants, which are combined to build the model. These are:

- domestic share for intermediate inputs in Germany derived from the national Input-Output Table on a goods- and service-level (59 sectors),

- the federal states' regional shares of the national sector production; and

- $\quad$ pairwise distances between geometric centers of the sixteen federal states.

The first central parameters in the allocation model are the intraregional shares of inputs for the regional production, which also are referred to as domestic shares (in a regional context). These domestic shares must be calculated for all sectors and regions. The algorithm used estimates these domestic input-shares (DIS) by using the national domestic input-share (ndis) as a maximum and distributing regional values according to the regions' shares of the national sector production (rps). The ndis-values are calculated by using the Germany's Input-Output-Tables.

$$
D I S_{i j}=n d i s_{i} \cdot\left(1-e^{b_{i} \cdot \sqrt{r p s_{i j}}}\right)
$$

The values for the regional DIS are calculated by sectors $i=1, \ldots, 19$ (12) and regions $j=1, \ldots, 16$. The parameter $b$ determinates the distribution of the DIS below ndis. The higher the regional share (rps) the lower is the difference to the maximum. This approach was proposed in [13]. The authors provide an overview of domestic shares used in several regional studies and derive sectoral values for 97 Regions in Germany. The parameters $b_{i}$ used for the 16 federal states are set to approximately match corresponding values for each sector in the literature [13-15]. They range from -1.0 to -1.6 . For operation and maintenance the ndis-values and b-parameters are set to absolute higher values, as we assume that these demands have a more local impact. The regional shares of sectoral production are estimated by using employment data. They are mean-standardized to form the rps-values.

Given the cost structure of the technology (manufacturing of wind turbines), the sectoral domestic input shares can be weighted to form an indicator of the extent to which a region is involved in regional wind energy use. It also can be called the local content of goods and services delivered for the production of wind turbines, as well as their installation and use in a region. In Figure 2, the weighted DIS-values are shown in a graph, in which the states are sorted by their GDP. Displayed is the overall DIS for the First-round effect according to the model results (see Section 3.2). It shows the extent to which possible demand "stays" within the regions. But the order of the states also shows how the regional economies correspond to the structure of preliminary inputs for wind energy use. The DIS-values decline with decreasing GDP. Some states show larger intraregional shares than one would expect according to their GDP-weight. In manufacturing, most of the territorial states would get higher ranks according to the intraregional share. City-states would have lower ranks compared to their GDP-range, as their market share in manufacturing products is lower. This disadvantage is not significant for inputs needed for the operation phase, because the input-vector shows a need for corporate services which is much higher compared to that of manufacturing. In this case a few eastern states have lower shares than according to their GDP. This analysis shows that not only the regions' economic weight but also the economic structure have a strong impact on the local content of 
producing and operating wind mills. These influencing factors even gain in importance in the next step, the interregional linkages in input delivery.

Figure 2. Domestic input-shares of the federal states, sorted by regional GDP.
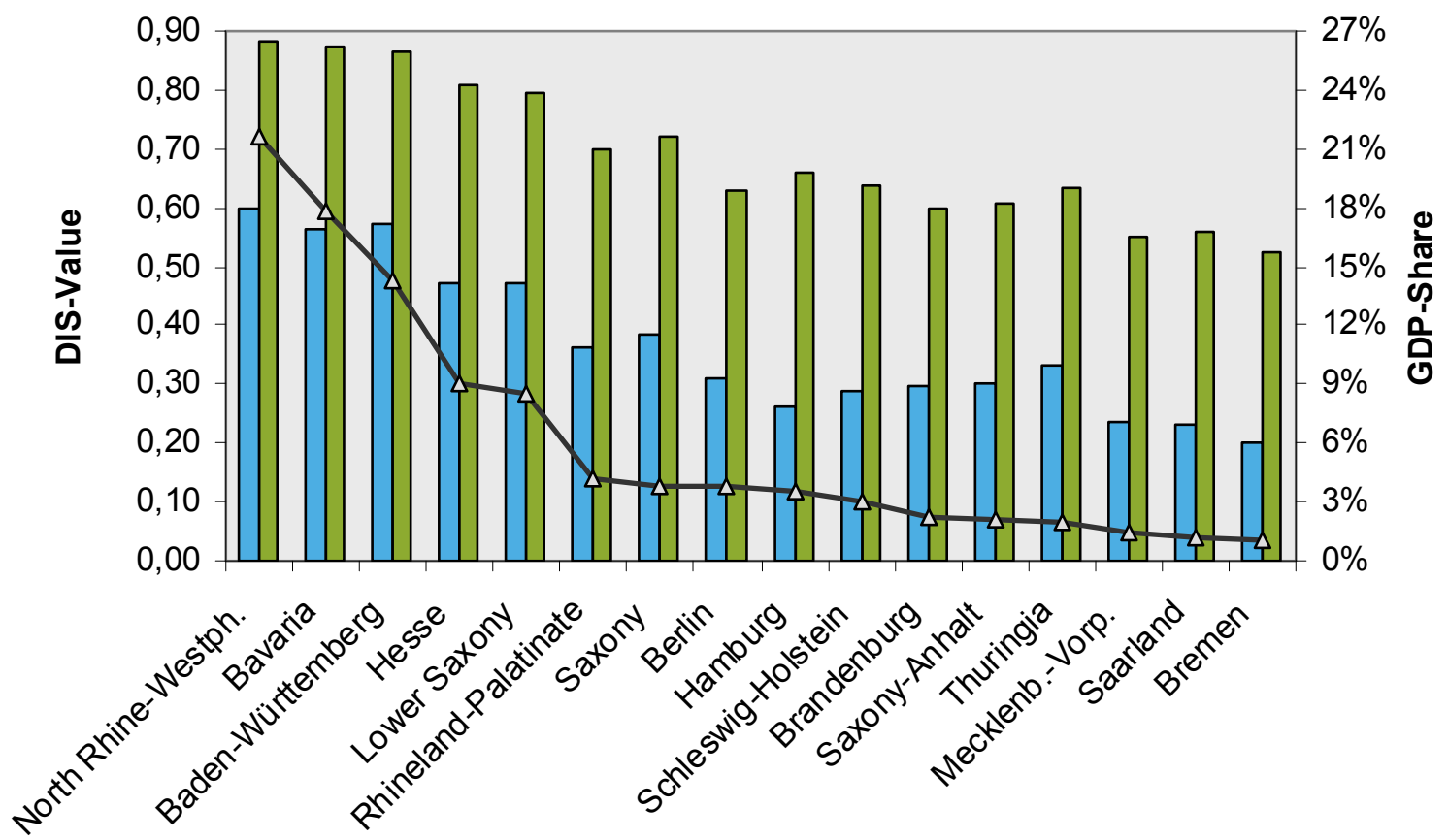

Manufacturing $\longleftarrow$ Operation/maintenance $\neg-$ GDP-Share

The second central parameter in the allocation model is the delivery share from region $k$ to region $j$. The shares are calculated by identifying gravitation values (GV) in a general distance function [16].

$$
G V_{j k}=\frac{r p_{k}}{D_{j k}^{\beta}}
$$

Table 3. Fictitious example for calculation of an allocation matrix, three regions (ndis $=0.75=\beta ; b=-1.5$ ).

(a) Distances and regional production (Input for calculation).

\begin{tabular}{ccccc}
\hline & \multicolumn{3}{c}{ Input delivery (k) } \\
\hline Distance d $(\mathrm{km})$ & & A & B & C \\
& A & & 250 & 320 \\
Input reception (j) & B & 250 & & 90 \\
& C & 320 & 90 & \\
Production (rp) & & 700 & 250 & 400 \\
Production share & & $51.9 \%$ & $18.5 \%$ & $29.6 \%$ \\
Standardized (rps) & & 1.56 & 0.56 & 0.89 \\
\hline
\end{tabular}


Table 3. Cont.

(b) Domestic input-shares.

\begin{tabular}{cccc}
\hline & A & B & C \\
\hline Domestic input-share (DIS) & 0.63 & 0.50 & 0.57 \\
\hline
\end{tabular}

(c) Gravitation values (GV).

\begin{tabular}{cccccc}
\hline \multirow{2}{*}{\begin{tabular}{c} 
Gravitation values, \\
\multicolumn{2}{c}{ sector $i$}
\end{tabular}} & \multicolumn{4}{c}{ Input delivery (k) } \\
\cline { 2 - 6 } & $\mathrm{A}$ & $\mathrm{B}$ & $\mathrm{C}$ & Sum \\
\hline Input & $\mathrm{A}$ & & 3.98 & 5.29 & 9.26 \\
reception & $\mathrm{B}$ & 11.13 & & 13.69 & 24.82 \\
$(j)$ & $\mathrm{C}$ & 9.25 & 8.56 & & 17.81 \\
\hline
\end{tabular}

(d) Allocation matrix including domestic input shares.

\begin{tabular}{cccccc}
\hline \multirow{2}{*}{\begin{tabular}{c} 
Allocation matrix, \\
\multicolumn{2}{c}{ sector $i$}
\end{tabular}} & \multicolumn{4}{c}{ Input delivery $(\mathrm{k})$} \\
\cline { 2 - 6 } & $\mathrm{A}$ & $\mathrm{B}$ & $\mathrm{C}$ & Sum \\
\hline Input & $\mathrm{A}$ & 0.63 & 0.16 & 0.21 & 1.00 \\
reception & $\mathrm{B}$ & 0.22 & 0.50 & 0.27 & 1.00 \\
$(j)$ & $\mathrm{C}$ & 0.22 & 0.21 & 0.57 & 1.00 \\
\hline
\end{tabular}

The higher the production in region $k$ (rp) the higher is the gravitation value. With increasing distance $\mathrm{D}(\mathrm{km})$ between region $j$ and region $k$, GV gets lower, while $\beta$ is a parameter to determine the influence of distance. They were set to the ndis-Parameter (see Formula 1). Over all regions $k$, the delivery shares sum up to $1-\mathrm{DIS}_{i j}$ to build an allocation matrix. They are calculated for each sector. Table 3 shows the procedure of a fictitious example with three regions. Table 3(a) shows the distances between the regions $\mathrm{A}, \mathrm{B}$ and $\mathrm{C}$ as well as the regional production. The domestic input-shares are calculated in Table (b) using the mean-standardized production shares (Formula 1). In Table (c) the distance values according to Formula 2 are calculated. The domestic input shares are implemented in the diagonal of the allocation matrix in Table (c). The transformed distance values are fitted in to define the deliveries from each region to another.

The allocation model was defined separately for manufacturing as well as operation and maintenance. The gravitation values were assumed to be more neighborhood-based in the case of operation and maintenance. The regional shares and production were estimated by using employment data. In the end 43 allocation matrices were calculated: 19 for manufacturing and 12 for operation/maintenance for first-round effects, as well as 12 for further multipliers. The number of sectors for the allocation model (starting with 59 in the national model) was defined according to the diversification of inputs of the specific input-output structure. As a result the regional outcome of indirect effects is highly dependent on regional economic structures and locations. The net effect in a regional context is the balance of in- and outflow of regional demand for preliminary inputs.

To classify the approach concerning input-output analysis, it is important to know that only intermediate linkages are subject of the model. Inaccuracies therefore predominantly occur concerning the origin of the intermediate inputs needed for regional production. The share of (international) export and import of preliminary inputs in relation to total input needed is assumed to be the same in every 
region. Thus one of the actual methodological challenges is related to the unknown intraregional share of domestic input delivery, which is of major importance in a regional input-output approach [10,11]. The second task is the provision of information about the origin of interregional deliveries.

\section{Gross Employment Effect of Onshore Wind Energy Technology in Germany 2009 by Regions}

In the following, we show the results of direct employment and indirect employment in the wind energy sector in the year 2009.

\subsection{Direct Employment in 2009}

The results show that direct employment of wind energy is rather concentrated in northern Germany. For both manufacturing and operation employment is highest in Lower Saxony with over 13,000 persons. This represents over $0.4 \%$ of the total employment in this region. The relative weight is even higher in Saxony-Anhalt (0.6\%), where over 5,600 persons are directly employed in the sector. The least relevance of wind energy (onshore) for direct employment can be observed in the Southwest, even though these states contribute a large absolute number of employees to Germany's total employment. Obviously, the impact of wind energy expansion is highest in the Northwest and the Middle of Eastern Germany. This distribution originally is related to the favorable natural conditions for the use of wind energy. Only in the city-states and Mecklenburg-Vorpommern, the direct effect is lower in absolute and relative terms. Figure 3 also shows that Bavaria has a high absolute number of employees. A high share of component manufacturers is located there. The relative importance is similar to its neighbors.

Figure 3. (a) The 16 federal states (Bundesländer) and major areas; (b) Distribution of the absolute number of employees (wind energy, direct); (c) Distribution of the employment ratio (wind energy, direct).

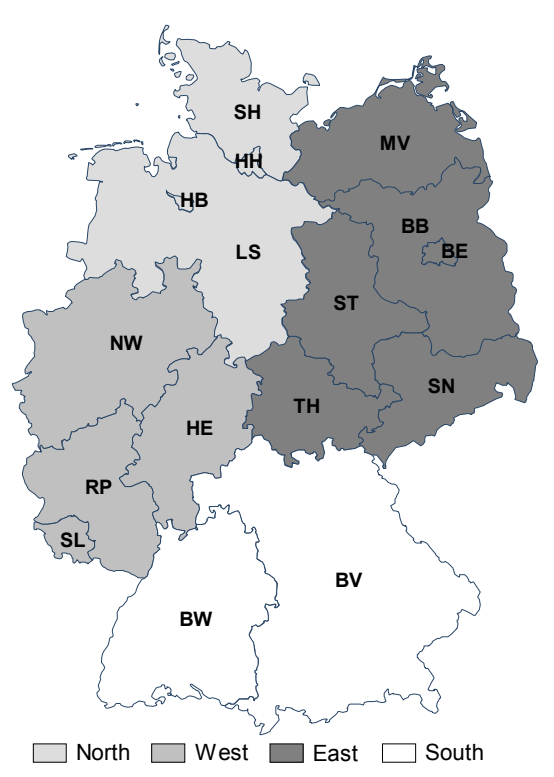

(a)

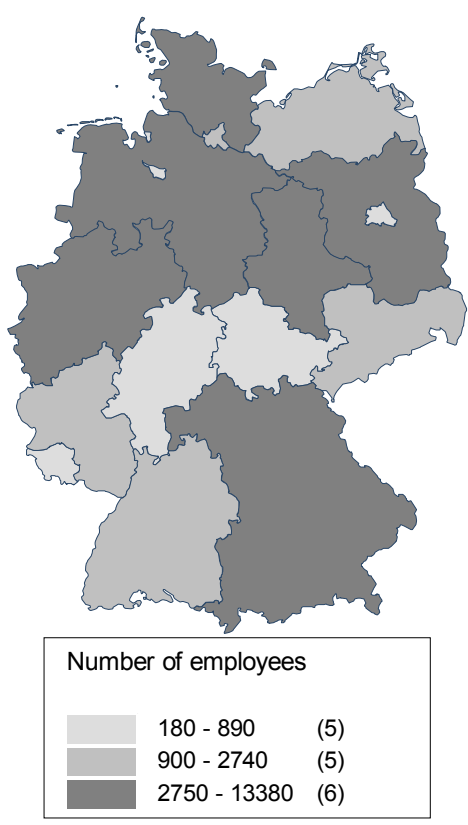

(b)

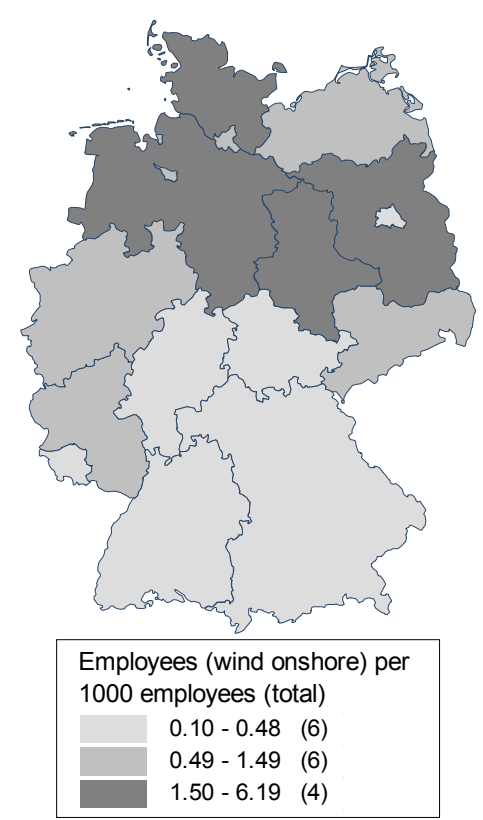

(c) 


\subsection{Indirect Employment in 2009}

The regional distribution of indirect employment is different to the one for direct employment. Large (territorial) states with a substantial share of national manufacturing can benefit from preliminary inputs to wind energy manufacturing and operating. In some federal states with a low share of direct effects, the sum of indirect employment is higher than in those with a high share of direct effects. In comparison to total regional employment, the values are highest in Lower Saxony and Saxony-Anhalt. Approximately every 300th employee is attributed to indirect effects derived from the wind industry in these regions. In contrast to the total amounts, the relative employment in Baden-Württemberg, Bavaria and North Rhine-Westphalia is slightly below average $(0.15 \%)$.

The regions with the highest indirect employment in manufacturing are North Rhine-Westphalia, Lower Saxony, Bavaria and Baden-Württemberg (66\%). Substantially lower values are located in Hesse, Saxony-Anhalt, Saxony and Rhineland-Palatinate. But they still sum up to more than $20 \%$ of the 42,940 employees in manufacturing. The regional distribution of employment for operation and maintenance also changes, if one compares indirect and direct effects. The highest indirect employment can be found in Lower Saxony, North Rhine-Westphalia and Schleswig-Holstein. Approximately half of the 12,510 employees in Germany are concentrated in these regions. Despite the low prevalence of installations in the south of Germany, Bavaria and Baden-Württemberg hold the fourth and fifth rank in indirect employment. Over 1400 employees can be assigned to Saxony-Anhalt and Brandenburg. While those two states are also characterized as having large shares of the total capacity, Hesse additionally can profit from the interregional demand.

Demand created by indirect effects of wind energy expansion is subject to a strong recirculation between regions. Figure 4 shows the dominating directions of reallocation on an aggregated level of four major regions. They show both indirect employment in the areas and how it is composed of intra- and interregional flows according to the model. The map shows that deliveries from the West to the North are especially meaningful. Twenty four percent of indirect employment in the West is connected with these flows, i.e. 4100 jobs in total. Approximately $9 \%$ of gross employment in the North is due to deliveries to the East. These are 1,400 employees. Despite the long distance 20\% of gross employment in the South is connected to deliveries to the North (around 2,600 employees of 13,240 in total). It becomes apparent that, especially the West, but also the South, benefit from preliminary input delivery to the other areas. Around $45 \%$ of the total indirect employment is generated in the North and East, but predominantly for supply to their own areas (around 76\%). In the West and the South only $50 \%$ are connected to intraregional supplies. 
Figure 4. Interregional linkages in indirect employment effects.

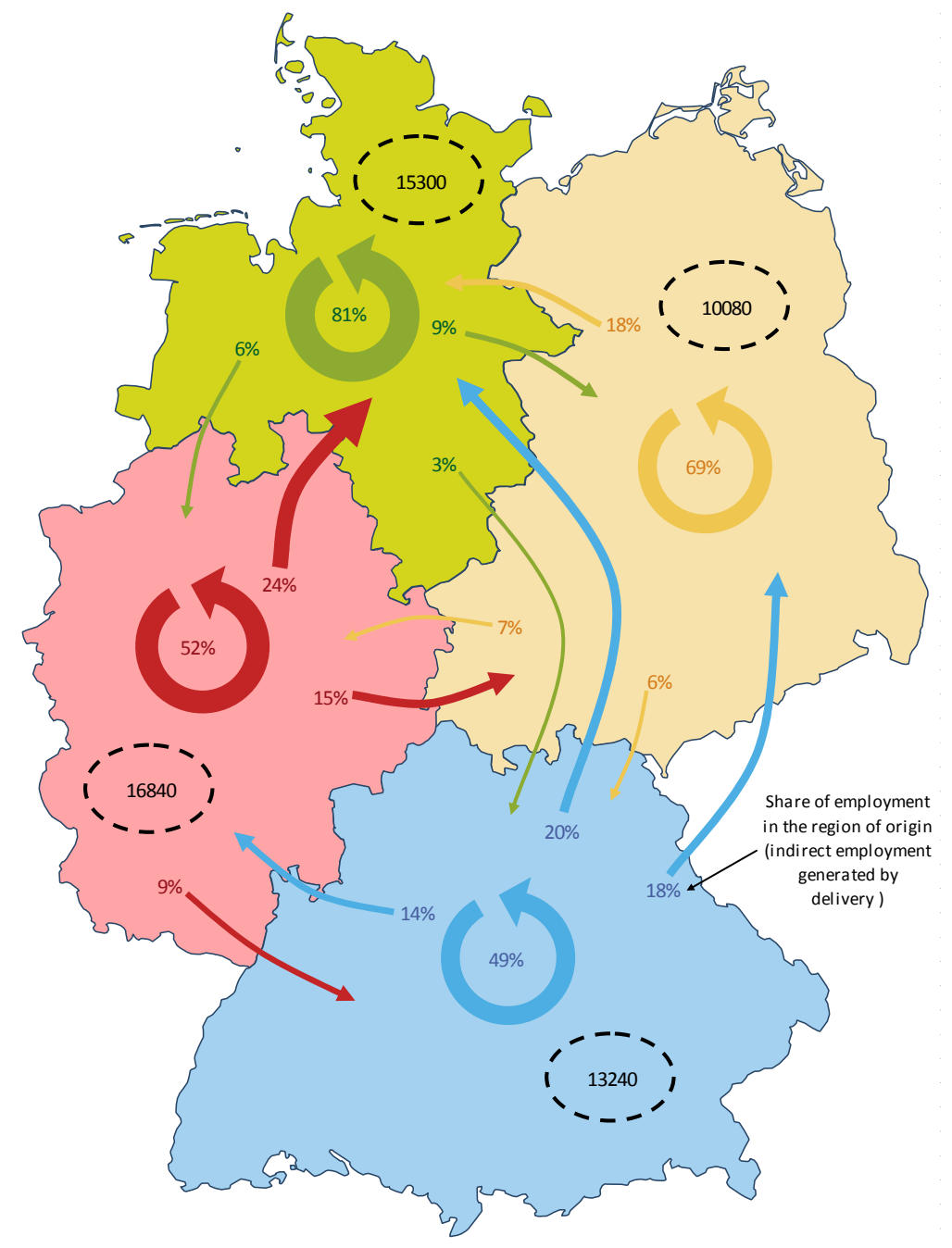

\subsection{Summary}

On average every 370th employee in Germany is related to the expanded use of wind energy and facility exports. This complies with 2.7 wind-energy employees (direct and indirect) per 1000 employees in total. The results are shown in Table 4 and Figure 5. Summing up, the regional distribution of gross employment in wind energy onshore is dominated by a north-south-divide. However, there are spatial patterns which overlap this basic statement corresponding to the natural conditions. On the one hand states like Saxony-Anhalt and Brandenburg clearly can participate in the development of the wind industry. This is apparent especially concerning the relative importance in the regions. On the other hand, the analysis shows that the states North-Rhine Westphalia, Baden-Württemberg and Bavaria only have low relative importance, though over $34 \%$ of direct and indirect employment is located in this part of Germany. The economic participation of these regions on the one hand is due to the needed supply of specialized components for the wind industry; but it also is a result of the regions' high competitiveness in providing equipment and inputs. North-Rhine Westphalia especially can profit from the low distances to the wind industry in the North, but also from specialization in metal products. Also other regions show a remarkably high influence of indirect employment, such as Hesse, Rhineland Palatinate, Saxony and Thuringia. 
Table 4. Wind energy onshore: Federal states' shares in gross employment in 2009.

\begin{tabular}{lccccc}
\hline & $\begin{array}{c}\text { Employment } \\
\text { (direct and } \\
\text { indirect) }\end{array}$ & $\begin{array}{c}\text { Share of } \\
\text { national } \\
\text { employment }\end{array}$ & $\begin{array}{c}\text { Share of total } \\
\text { regional } \\
\text { employment }\end{array}$ & $\begin{array}{c}\text { Share } \\
\text { Operation and } \\
\text { maintenance }\end{array}$ & Acronym \\
\hline Germany & 95,590 & $100.0 \%$ & $0.267 \%$ & $18 \%$ & \\
Federal states & 7,300 & $7.6 \%$ & $0.146 \%$ & $12 \%$ & $\mathrm{BW}$ \\
Baden-Württemberg & 9,750 & $10.2 \%$ & $0.168 \%$ & $9 \%$ & $\mathrm{BV}$ \\
Bavaria & 1,630 & $1.7 \%$ & $0.116 \%$ & $17 \%$ & $\mathrm{BE}$ \\
Berlin & 4,940 & $5.2 \%$ & $0.536 \%$ & $26 \%$ & $\mathrm{BB}$ \\
Brandenburg & 1,140 & $1.2 \%$ & $0.312 \%$ & $27 \%$ & $\mathrm{HB}$ \\
Bremen & 2,330 & $2.4 \%$ & $0.234 \%$ & $24 \%$ & $\mathrm{HH}$ \\
Hamburg & 3,470 & $3.6 \%$ & $0.125 \%$ & $19 \%$ & $\mathrm{HE}$ \\
Hesse & 1,710 & $1.8 \%$ & $0.260 \%$ & $28 \%$ & $\mathrm{MV}$ \\
Mecklenburg-Vorpommern & 24,180 & $25.3 \%$ & $0.739 \%$ & $20 \%$ & $\mathrm{LS}$ \\
Lower Saxony & 15,660 & $16.4 \%$ & $0.200 \%$ & $15 \%$ & $\mathrm{NW}$ \\
North Rhine-Westphalia & 3,750 & $3.9 \%$ & $0.228 \%$ & $18 \%$ & $\mathrm{RP}$ \\
Rhineland-Palatinate & 630 & $0.7 \%$ & $0.135 \%$ & $14 \%$ & $\mathrm{SL}$ \\
Saarland & 3,300 & $3.5 \%$ & $0.190 \%$ & $16 \%$ & $\mathrm{SN}$ \\
Saxony & 8,340 & $8.7 \%$ & $0.906 \%$ & $13 \%$ & $\mathrm{ST}$ \\
Saxony-Anhalt & 5,890 & $6.2 \%$ & $0.527 \%$ & $37 \%$ & $\mathrm{SH}$ \\
Schleswig-Holstein & 1,570 & $1.6 \%$ & $0.172 \%$ & $23 \%$ & $\mathrm{TH}$ \\
Thuringia & & & & & \\
\hline
\end{tabular}

Figure 5. (a) Distribution of the absolute number of employees (wind energy, total) (b) Distribution of the employment ratio (wind energy, total).

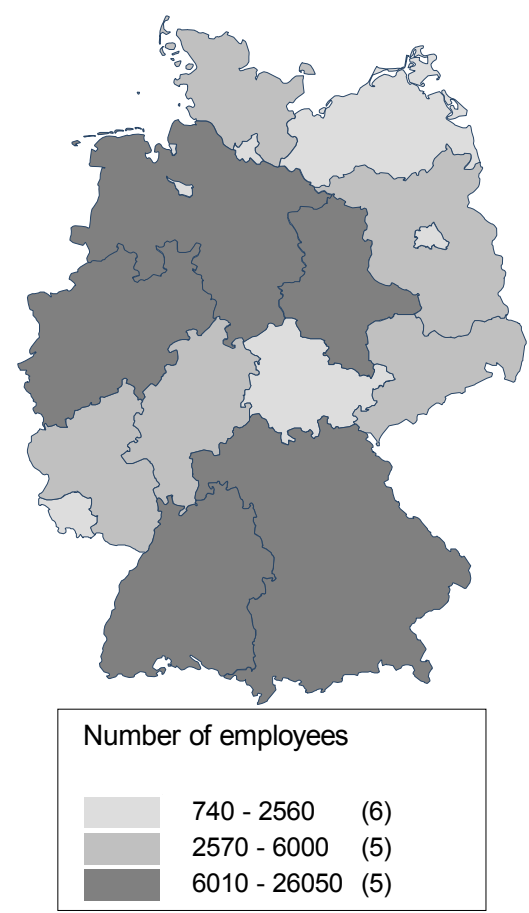

(a)

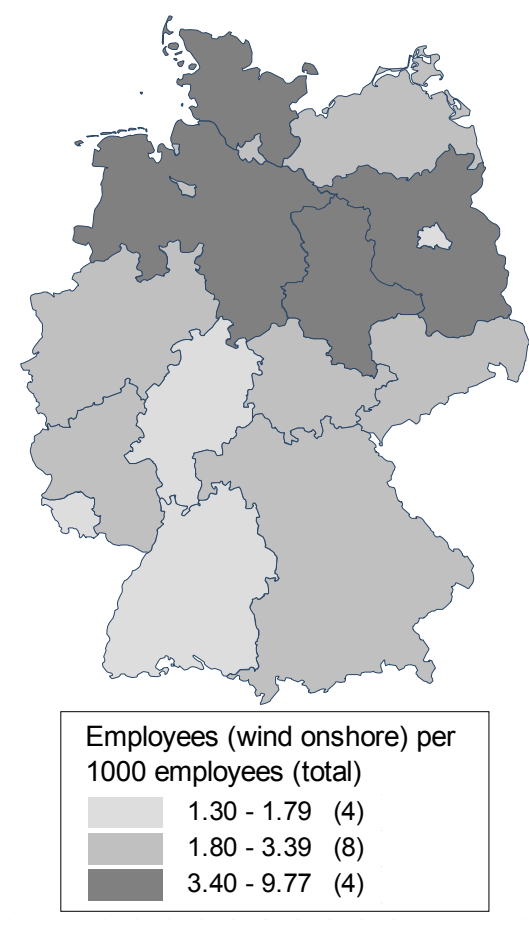

(b) 


\section{Outlook on Future Perspectives of Employment}

Our last topic addresses the future perspectives of employment impacts of wind energy onshore from a regional perspective. The recent national study shows, that there is not only one reasonable development of RE-technologies in Germany. Subject to the price of fossil energy, the national capacity building in RE-technologies, according to governmental scenarios and the export shares of the German wind energy technologies, amount to some 24 scenarios, which represent both likely or rather unlikely future developments but elucidate a possible range. For clarity, we selected one of these 24 scenarios as a base for the regional pilot modeling approach. We chose one with a rather high export share (the second highest share in 2030 among four); a low price level for fossil energy (lowest of two price paths); and a political scenario corresponding to the Lead Scenario 2009 [17]. Under these assumptions the gross employment impact of wind energy onshore in Germany reaches approximately 165,000 persons in 2030. Due to a rather dynamic development of Germany's exports of wind energy turbines and their components up to about 2020, the expected employment impacts in this period grow outstandingly fast (nearly $5 \%$ per anno). Afterwards the export growth rate is expected to slow down considerably with corresponding consequences for the employment impacts of wind energy onshore technology in Germany. New domestic installations also slow down after 2015; most efforts here go into off-shore installations. However, repowering will still be of some importance, also depending on the development of political support for repowering.

Yet what are the consequences for employment impacts on a regional level? Will all of Germany's states gain in the same way? Or are regional differences in the future development to be expected?

As for the status-quo analysis for the year 2009, detailed information from the national study serve as important information for the regional model. Of special interest are the national results for the different components of gross employment impacts. As could be seen from the results of 2009, some states are exceptionally strong in the (direct) production of onshore wind turbines and their components, in others the main employment impacts result from the (indirect) production of intermediate products that are demanded by the wind industry. A third group is characterized by high shares of the installed capacity and therefore an above-average share of employment in the field of operation and maintenance. With this in mind, future differences in the growth dynamics between the components are likely to have an impact on regional employment perspectives.

To assess future developments in model projections, the above presented indicators (e.g., regional shares of installed capacity) have to be available for the coming years. While national values are available in the scenario framework of the national study, further assumptions are necessary on a regional level. For the projections performed in the pilot study, these hypotheses were developed further to generate the distribution of capacity among regions and among wind power systems manufacturers up to 2030. In addition, differences in the export orientation on a regional level were set. These hypotheses and assumptions are tackling the following questions:

- Is it likely that the regional distribution of wind turbine manufacturers within Germany will shift in the future? For example, this could be founded in (regional) differences in export orientation. 
- Is it likely that the regional distribution of installed capacities within Germany will shift in the future? For example, this could be ascribed to (regional) differences in the political environment and in wind energy potentials.

- As shown above, the regional shares of national production of good i (together with other parameters) explain the regional shares within the allocation matrices for the localization of indirect employment effects. Therefore, expectations of future differences in regional growth patterns (in a sectoral perspective) are likely to have influence on the regional distribution of indirect employment effects of the RE-technologies.

- The production values are subject to the allocation matrices for the localization of indirect employment effects. To calculate the employment induced by this production, regional differences in labor productivity have to be considered. This holds true, not only for the model based calculations for 2009 , but also for the projection part, so that the future development of labor productivity from a regional (and sectoral) perspective has to be implemented.

Under these assumptions the regional pilot model for wind energy onshore shows that employment impacts tend to shift from the North and West to the West and South, but all federal states can benefit from the future development. The largest absolute increase in gross employment can be seen in Lower Saxony and North-Rhine Westphalia. The federal states Hesse, Berlin and Baden-Württemberg show the highest relative growth.

\section{Conclusions}

The renewable energy industry in Germany employed roughly 400,000 people in 2010. Wind industry contributed nearly 100,000 people to this workforce [5]. Besides the annual provision of national figures, the assessment of regional value-added, generated by the expansion of RE-technologies is a highly important issue, when political measures are discussed on a regional and local level. It provides political actors with information about how the change to a sustainable energy production affects national and regional economies. In this paper, regional employment was analyzed in the context of investment (incl. export of facilities) and operation in wind energy use (onshore). For the estimation of the 16 federal states in Germany both direct employment and indirect employment generated by intermediate demand were taken into account. For the estimation of direct employment related to the manufacturing process, data from a nation-wide survey and other studies was combined. The employment related to the operation of wind energy plants was regionalized according to installed capacities by region and by manufacturers. Confronted with the absence of a complete set of regional input-output tables, a new approach for estimating the distribution of indirect effects is introduced. The allocation model combines empirically based assumptions about intraregional shares of intermediate inputs and interregional flows. By applying them to a detailed structure of goods and services it is highly applicable to additional-demand scenarios with regard to a specialized product like a wind turbine. The results show, that every federal state benefits in terms of additional employment, especially those with capacities for manufacturing wind turbines and its major components. Also gross employment generated in the phase of operation is of importance in Germany (18\% of gross employment) and generates jobs in every federal state. This is not the case if one only takes direct effects into consideration. Especially for operation and maintenance, direct employment is very low in 
several states. Employment directly related to both manufacturing and operation of wind energy onshore is rather concentrated in northern Germany. However, the modeling results for the localization of employment effects, associated to the intermediate demand, show that indirect effects also make regions profit which have a high capacity to deliver the products and services needed for production and operation of wind-mills, and which are located in the neighborhood of the facilities on the different stages of the production process. Indirect effects spread out over the whole country and, although they are not evenly distributed among the regions, one can see that gross employment can greatly benefit also in the federal states in the south of Germany.

The estimation approach for regional indirect effects, takes into account many parameters generated by detailed national and regional data. In general though, there is a deficit in empirical evidence about how regions interact, especially in preliminary inputs. Further research will be channeled into extending datasets and new quantitative analyses to better assess the influencing factors. Besides this, the methods for regional projections need to be developed further. It already becomes apparent, however, that only one "predictable" value is of minor use in this context. Sets of scenarios and assumptions have to be combined to assess possible development paths and ranges of employment impacts.

Regions, which make great efforts to build capacities for energy generated locally, not only can generate value added by more self-sufficiency and fiscal effects, they also generate conditions for new jobs, as operation and maintenance always requires a certain local content.

\section{Acknowledgments}

This work has been supported by the German Federal Ministry for the Environment, Nature Conservation and Nuclear Safety. We thank two anonymous reviewers for their helpful comments and suggestions.

\section{Conflict of Interest}

The authors declare no conflict of interest.

\section{References and Notes}

1. Staiß, F.; Kratzat, M.; Nitsch, J.; Lehr, U.; Edler, D.; Lutz, C. Erneuerbare Energien: Arbeitsplatzeffekte-Wirkungen des Ausbaus erneuerbarer Energien auf den deutschen Arbeitsmarkt; Research project on behalf of the Federal Environment Ministry (BMU); BMU: Berlin, Germany, 2006.

2. Kratzat, M.; Lehr, U.; Nitsch, J.; Edler, D.; Lutz, C. Erneuerbare Energien: Arbeitsplatzeffekte 2006-Wirkungen des Ausbaus erneuerbarer Energien auf den deutschen Arbeitsmarkt-Follow up; Research project on behalf of the Federal Environment Ministry (BMU); BMU: Berlin, Germany, 2007. 
3. Lehr, U.; Lutz, C.; Edler, D.; O’Sullivan, M.; Nienhaus, K.; Simon, S.; Nitsch, J.; Breitschopf, B.; Bickel, P.; Ottmüller, M. Kurz- und langfristige Auswirkungen des Ausbaus der erneuerbaren Energien auf den deutschen Arbeitsmarkt; Research project on behalf of the Federal Environment Ministry (BMU); BMU: Berlin, Germany, 2011.

4. Staiß, F.; Kratzat, M.; Nitsch, J.; Lehr, U.; Edler, D.; Lutz, C. Renewable energy and employment in Germany. Energy Policy 2008, 36, 108-117.

5. O’Sullivan, M.; Edler, D.; van Mark, K.; Nieder, T.; Lehr, U. Gross Employment from Renewable Energy in Germany in 2010: A First Estimate; Research Project on behalf of by the Federal Environment Ministry (BMU); BMU: Berlin, Germany, 2011.

6. Blazejczak, J.; Braun, F.G.; Edler, D.; Schill, W. Economic Effects of Renewable Energy Expansion: A Model-Based Analysis for Germany; DIW Discussion Papers 1156; DIW: Berlin, Germany, 2011.

7. Diekmann, J.; Groba, F.; Vogel-Sperl, A.; Püttner, A.; van Mark, K.; Mayer, J.; Ziller, U. Bundesländer-Vergleichsstudie mit Analyse der Erfolgsfaktoren für den Ausbau der Erneuerbaren Energien 2010; Endbericht; DIW: Berlin, Germany, 2010.

8. Distelkamp, M.; Bickel, P.; Ulrich, P.; Lehr, U. Erneuerbar beschäftigt in den Bundesländern: Ausgewählte Fallstudien sowie Pilotmodellierung für die Windenergie an Land; Research project on behalf of the Federal Environment Ministry (BMU); BMU: Berlin, Germany, 2011.

9. Lutz, C.; Meyer, B.; Nathani, C.; Schleich, J. Endogenous innovation, the economy and the environment: Impacts of a technology-based modelling approach for energy-intensive industries in germany. Energy Stud. Rev. 2007, 15, 2-18.

10. Harris, R.; Liu, A. Input-output modelling of the urban and regional economy: The importance of external trade. Regional Stud. 1998, 32, 851-862.

11. Münzenmaier, W. Interregional input-output analysis for the Federal Republic of Germany-The compilation of an interregional-interindustrial system of economic flows between two regions, and some consequences for regional analyses. Jahrb. Regionalwissenschaft 1987, 8, 15-39.

12. The German Institute for Economic Research (DIW) provides detailed input-tables for all RE-technologies separately since 2006. The calculations are based on national surveys and are documented in Lehr et al. 2011.

13. Färber, G.; Dalezios, H.; Arndt, O.; Steden, P. Die Formale und effektive Inzidenz von Bundesmitteln-Endbericht; Research project on behalf of the Federal Ministry of Transport; Building and Urban Development and the Federal Office for Building and Regional Planning: Speyer, Germany, 2007.

14. Stäglin, R. A step by step procedure to regionalized input-output analysis. In Regional Input-Output Analysis-Conceptual Issues, Airport Case Studies and Extensions; HWWA Studies 66; Pfähler, W., Ed.; Nomos: Baden-Baden, Germany, 2001.

15. Oberhofer, W.; Haupt, H. Derivation and application of regionalized input-output tables: A case study. In Regional Input-Output Analysis-Conceptual Issues, Airport Case Studies and Extensions; HWWA Studies 66; Pfähler, W., Ed.; Nomos: Baden, Germany, 2001.

16. Isard, W. Gravity and spatial interaction models. In Methods of Interregional and Regional Analysis; Isard, W., Azis, I.J., Drennan, M.P., Miller, R.E., Saltzmann, S., Thorbecke, E., Eds.; Ashgate: Aldershot, UK, 1998. 
17. Nitsch, J.; Wenzel, B. Leitszenario 2009. Langfristszenarien und Strategien für den Ausbau erneuerbarer Energien in Deutschland unter Berücksichtigung der europäischen und globalen Entwicklung; Study on behalf of the Federal Environment Ministry (BMU); BMU: Berlin, Germany, 2009.

(C) 2012 by the authors; licensee MDPI. Basel. Switzerland. This article is an open access article distributed under the terms and conditions of the Creative Commons Attribution license (http://creativecommons.org/licenses/by/3.0/). 